\title{
Consciência histórica e representações sociais: um estudo acerca das percepções de jovens estudantes sobre o Brasil $^{1}$
}

\author{
Aaron Sena Cerqueira Reis ${ }^{2}$ \\ ORCID: 0000-0001-8970-4941 \\ Joilson Pereira da Silva ${ }^{3}$ \\ ORCID: 0000-0001-9149-3020
}

\section{Resumo}

Neste artigo, analisamos as percepções de jovens estudantes sobre o Brasil a partir do diálogo entre as teorias da consciência histórica e das representações sociais. Mediante a produção de narrativas escritas, buscamos identificar as visões de mundo que os participantes utilizam para orientar-se no tempo e perspectivar seu futuro. Com isto, intentamos valorizar as construções mentais de sujeitos em situação escolar, contribuindo com o fortalecimento das pesquisas no âmbito do Ensino de História. 0 estudo foi realizado em uma escola pública estadual, localizada no bairro Butantã, na cidade de São Paulo/SP, no ano de 2017. Participaram 127 estudantes, entre 14 e 18 anos de idade, dos gêneros masculino e feminino, distribuídos em cinco turmas do $1^{\circ}$ ano do Ensino Médio. Os dados foram coletados a partir de um questionário e analisados segundo os pressupostos da Grounded theory com auxílio do IRAMUTEQ. Este software viabilizou a construção de um dendograma composto por três classes que implicaram a identificação de representações sobre o tempo presente (classe 1), articulações com o passado (classe 2) e projeções para o futuro (classe 3). De acordo com os resultados, evidenciamos ideias relacionadas à percepção de um país em crise, com um passado preconceituoso e um futuro, contraditoriamente, promissor. Trabalhadas em sala de aula, essas ideias podem contribuir com a formação da consciência histórica dos estudantes.

\section{Palavras-chave}

Ensino de história - Consciência histórica - Representações sociais - Jovens - Escola pública.

\footnotetext{
1- Trabalho realizado com apoio da Coordenação de Aperfeiçoamento de Pessoal de Nível Superior (CAPES).

2 - Universidade Tiradentes, Aracaju, Sergipe, Brasil. Contato: aaron_sena@hotmail.com

3- Universidade Federal de Sergipe, São Cristóvão, Sergipe, Brasil. Contato: joilsonp@hotmail.com
} 


\section{Historical consciousness and social representation: a study on the perceptions of young students about Brazil*}

\section{Abstract}

In this article, we analyze the perceptions of young students about Brazil, starting from the dialogue between the historical consciousness and social representations theories. Through the production of written narratives, we aim to identify the worldviews which our participants use to guide themselves over time and to envision their future. Therewith, we intend to value the mental constructions of the subjects in the school context contributing to the strengthening of research in the field of Teaching of History. This study was carried out in a public state school located in the Butantã neighborhood, in the city of São Paulo/SP, Brazil, in 2017. It was part of it 127 students, between the ages of 14 and 18, males and females, distributed in five groups of the 1st grade of High School. The data was obtained through a questionnaire and analyzed accordingly with the assumptions of Grounded theory with the help of IRAMUTEQ. This enabled the construction of a dendrogram composed of three classes which implied in the identification of representations about the present time (class 1), articulations with the past (class 2), and projections for the future (class 3). Under the results, we evidenced ideas related to the perception of a country in crisis, with a prejudiced past and with a future, contradictorily, promising. Once worked in class, these ideas can contribute to the formation of the historical consciousness of the students.

\section{Keywords}

Teaching of History - Historical consciousness - Social representations - Young people Public school.

\section{Introdução}

Neste artigo, analisamos as percepções de estudantes do Ensino Médio sobre o Brasil a partir do diálogo entre as teorias da consciência histórica e das representações sociais. Mediante a produção de narrativas escritas, buscamos identificar as visões de mundo que os jovens utilizam para orientar-se no tempo e perspectivar seu futuro. Com isto, intentamos valorizar as construções mentais de sujeitos em situação escolar, contribuindo, assim, com o fortalecimento das pesquisas no âmbito do Ensino de História.

Resultado de um amplo debate, o Ensino de História consolidou-se como um campo de estudos e pesquisa ao destacar temas relacionados à formação de professores, à produção do conhecimento escolar, aos usos do livro didático e suas diferentes linguagens, às reformas curriculares, além da implementação de políticas educacionais (GUIMARÃES, 2012; OLIVEIRA, 2003). Seguindo uma perspectiva mais recente, privilegiamos, aqui, o estudo da consciência histórica, consubstanciado por meio de uma pesquisa de campo, 
a partir da qual nos envolvemos com um contexto educativo específico com o fito de desvendar, ao menos em parte, as relações de ensino-aprendizagem de História na sala de aula (CAIMI, 2015).

Considerando a necessidade de incorporar não apenas os/as professores/as, mas também os/as estudantes como sujeitos da constituição da História escolar, lançamos mão da teoria das representações sociais, abordagem da Psicologia Social que, no Ensino de História, nos permite "compreender a construção do conhecimento cotidiano, seus modos de funcionamento e uso na vida diária para entender os processos que estão na base das mudanças do pensamento e das práticas sociais” (ALMEIDA; SANTOS, 2011, p. 288).

\section{A consciência histórica na teoria de Rüsen}

Sob a perspectiva do historiador alemão Jörn Rüsen (2001, 2015), a consciência histórica pode ser compreendida como um elemento universalmente humano que, enraizada na historicidade da própria vida, denota um conjunto de ações ou intenções no tempo. Nesse sentido, a consciência histórica é um processo cognitivo que estabelece uma relação imediata entre passado e presente, garantindo projeções de futuro. Além disso, contribui com a formação da identidade, fenômeno capaz de moldar o "mundo da vida humana" e prover o eu com "continuidade e consistência" em uma relação cultural com seu grupo (RÜSEN, 2009, p. 174).

Como uma necessidade inerente ao ser humano, a consciência histórica viabiliza a interpretação da nossa experiência no tempo, favorecendo a construção do pensamento histórico que, inserido em uma lógica narrativa, estrutura e confere sentido aos eventos históricos. Objeto da matriz disciplinar de Rüsen (2015), o pensamento histórico constituise na relação entre: fatores que abarcam as dimensões da vida prática e da ciência especializada; práticas que denotam as estruturas comunicativas do pensamento, e; níveis de sentido que denotam as possibilidades de atribuição de significado ao passado.

Portanto, o pensamento histórico pode ser definido como um processo de metodização da História cujo resultado nos conduz a um tipo de conhecimento científico. Valendonos dos apontamentos de Assis (2010), podemos sintetizar que a partir do pensamento histórico metodizado, a ciência da História lida com verdades baseadas em critérios empírico, normativo e narrativo, favorecendo "interpretações do mundo humano sujeitas à complementação, à crítica e à superação por outras interpretações”. (ASSIS, 2010, p. 27).

Considerada como uma das operações do pensamento mais complexas, a interpretação "conecta os fatos do passado" por meio de uma "intersubjetividade controlável" que o investe de uma "função explicativa", produzindo, assim, o "saber histórico", apresentado em forma narrativa (RÜSEN, 2015, p. 171-186). Por sua vez, a narrativa tem elementos argumentativos que evidenciam o caráter científico da História e sua "relevância comunicativa”, ainda que atribuam diferentes sentidos à experiência desta natureza. Por conseguinte, a História pode basear-se nos modelos: tradicional, cujo sentido é "uno e duradouro"; exemplar, sintetizado na máxima "História mestra da vida"; crítico, baseado na negação de orientações prévias; e genético, cujo sentido é adquirido na mudança, permitindo que o passado seja conectado a diferentes formas de viver. 
Relacionada a esse pensamento, a consciência histórica é evidenciada a partir dos diferentes níveis de sentido e interpretada como um conjunto de ideias que partem das carências de orientação no tempo. Como um tipo específico de memória, suas operações somente são percebidas “quando se reconhece qual sua 'inserção na vida': por que ocorrem, que resultados alcançam na vida prática quotidiana dos que as realizam” (RÜSEN, 2001, p. 55).

Por meio dos diferentes níveis de constituição de sentido, a consciência histórica atravessa a matriz disciplinar de Rüsen e revela o processo vital da cultura histórica. 0 primeiro deles é o funcional, cuja constituição de sentido surge de maneira prévia, a exemplo da linguagem. Oposto a ele, surge o nível reflexivo, que se apropria e interfere no primeiro para construir subjetivamente novos sentidos. 0 terceiro nível, pragmático, opera uma mediação entre os anteriores, desse modo, “decisões prévias são incorporadas à produção do que pode ser um saber histórico com sentido” (RÜSEN, 2015, p. 97).

Para Rüsen $(2001 ; 2015)$, a consciência histórica é o próprio fundamento da ciência da História e, neste sentido, deve ser analisada como "fenômeno do mundo vital", isto é, "como uma forma da consciência humana que está relacionada imediatamente com a vida humana prática". Seu pressuposto é "a tese de que o homem tem de agir intencionalmente", de acordo com sua ação e paixão, para relacionar-se com a natureza, com os demais e consigo próprio (RÜSEN, 2001, p. 57). Este “superávit intencional do agir humano” denota uma distinção entre dois tipos de consciência do tempo que, apesar de dicotômicos, mesclam-se nas projeções que realizamos: a "experiência" e a "intenção" (RÜSEN, 2001, p. 58).

Articulados, esses elementos (experiência e intenção) compõem a "orientação do agir (e do sofrer) humano", operação mental em que o homem busca adequar suas intenções de agir conforme sua experiência no tempo. A consciência histórica é constituída, portanto, por meio da "transformação intelectual do tempo natural em tempo humano", sendo o "tempo natural" entendido como eventos contingentes e o "tempo humano" como as representações humanas sobre a própria vida (RÜSEN, 2001, p. 60).

Com esse breve panorama, quisemos mostrar a relevância do pensamento rüseniano no tocante às produções cujo foco recai não apenas sobre os processos de aquisição do conhecimento histórico, mas, também, na forma como esses saberes podem se relacionar com a vida prática de sujeitos em situação escolar. A seguir, adentramos na teoria das representações sociais na tentativa de estabelecermos um diálogo entre ambas as perspectivas.

\section{A teoria das representações sociais de Moscovici}

A teoria das representações sociais (TRS) tem origem na obra La psychanalyse, son image et son public (1961), do psicólogo romeno Serge Moscovici. Nela, o estudioso atribui ao senso comum o valor de um objeto que, originado na ciência, assume formas particulares na cultura. Desse modo, passou-se a rejeitar as diferentes correntes de pensamento que consideravam a popularização do conhecimento científico como um movimento capaz de desvalorizar ou deturpar a própria ciência (ALMEIDA; SANTOS, 2011).

De acordo com Sá (2002, p. 29, destaque do autor), “o termo representações sociais designa tanto um conjunto de fenômenos quanto o conceito que os engloba e a teoria construída para explicá-los, identificando um vasto campo de estudos psicossociológicos". 
Parafraseando Moscovici, o estudioso percebe que, não obstante à facilidade com que podemos captar a realidade das representações sociais, sua compreensão conceitual é mais complexa, tendo em vista que o próprio idealizador do campo "resistiu a apresentar uma defınição precisa" com receio de que essa tentativa reduzisse seu alcance conceitual (SÁ, 2002, p. 30). Tal posicionamento contribuiu, por outro lado, com a multiplicidade de perspectivas que conferem ao campo das representações sociais uma diversidade de objetos.

Esse fenômeno pressupõe a percepção do mundo a partir da construção de ideias que buscam responder aos "estímulos do ambiente físico ou quase físico, em que nós vivemos” (MOSCOVICI, 2011, p. 30). 0 processamento dessas informações gera um tipo de compreensão que deixa escapar algumas obviedades, como a transitoriedade do conhecimento ou a percepção de que nossas reações estão diretamente relacionadas a uma comunidade à qual pertencemos.

Para Moscovici (2011, p. 38), as representações definem-se como:

[...] entidades sociais, com uma vida própria, comunicando-se entre elas, opondo-se mutuamente e mudando em harmonia com o curso da vida; esvaindo-se, apenas para emergir novamente sob novas aparências.

Com isso, o intelectual sugere que:

[...] longe de serem receptores passivos, [as pessoas e os grupos] pensam por si mesmos, produzem e comunicam incessantemente suas próprias e específicas representações e soluções às questões que eles mesmos colocam. (MOSCOVICI, 2011, p. 45).

Em uma sociedade pensante, tais representações inserem-se no contraste entre dois universos que não possuem uma estrutura específica e, por isso, podem ser percebidos como representação ou ciência. No primeiro, destaca-se o universo consensual, cuja importância, alerta Moscovici (2011), consiste em tornar familiar, algo não familiar. Nesse aspecto, as representações evidenciam "imagens, ideias e a linguagem compartilhadas por um determinado grupo [que] sempre parecem ditar a direção e o expediente iniciais, com os quais o grupo tenta se acertar com o não familiar" (MOSCOVICI, 2011, p. 57). Em um lado oposto, têm-se o universo reificado, por meio do qual se recorre ao objeto conhecido para elaborar uma reconstrução racional, tornando, portanto, o familiar em não familiar.

No universo consensual, as operações cognitivas que resultam em representações são marcadas pelos processos de ancoragem e objetivação. Esses mecanismos atuam em nossa esfera particular, garantindo a compreensão e interpretação de um determinado objeto, o que nos capacita a reproduzi-lo e controlá-lo (MOSCOVICI, 2011).

A ancoragem pode ser definida como "um processo que transforma algo estranho e perturbador, que nos intriga, em nosso sistema particular de categorias e o compara com um paradigma de uma categoria que nós pensamos ser apropriada" (MOSCOVICI, 2011, p. 61). Nesse processo, escolhemos paradigmas ou protótipos estocados em nossa memória que nos permitem estabelecer comparações e, consequentemente, atribuir uma relação positiva ou negativa com alguém ou alguma coisa. Por outro lado, a nomeação 
está relacionada à necessidade de identificar coisas e seres, "ajustando-os em uma representação social dominante" (MOSCOVICI, 2011, p. 68).

Sendo um processo "mais atuante que a ancoragem", a objetivação denota que o "incomum e imperceptível para uma geração, torna-se familiar e óbvio para a seguinte" (MOSCOVICI, 2011, p. 71). Em outras palavras, a objetivação é o mecanismo que possibilita a materialização de abstrações, favorecendo a descoberta da qualidade icônica de uma ideia e a reprodução de um conceito em imagem. Embora nem todas as imagens sejam passíveis de representação, seja pela dificuldade de acesso ou por constituir-se em um tabu, o processo de seleção permite-lhes integrar um núcleo figurativo que evidencia um complexo de ideias. Para adquirir sentido, esse complexo precisa ser aceito e, posteriormente, assimilado pela sociedade. Desta forma, "as imagens se tornam elementos da realidade, em vez de elementos do pensamento" (MOSCOVICI, 2011, p. 74).

Em suma, a objetivação ocorre mediante seleção, formação de um esquema figurativo e naturalização. Esse mecanismo completa-se com a ancoragem, ou seja, o uso cotidiano da representação social de um dado objeto. Desenvolvidos paralelamente e em contexto, a separação entre os referidos esquemas é, tão somente, "analítica, um tanto artificial, mas necessária metodologicamente” (CARDOSO, 2012, p. 46).

\section{Diálogos entre a teoria da consciência histórica e a teoria das representaçōes sociais}

Algumas tentativas de estabelecer um diálogo entre as teorias da consciência histórica e a das representações sociais já ocorreram. Para Alves (2006, p. 13), por exemplo, é possível averiguar a construção de consciência histórica "a partir do encontro/ confronto em sala de aula, dos diferentes saberes oriundos do senso comum e da ciência da História, por meio da análise das representações sociais constituídas por seus sujeitos: alunos e professores". Em estudo de cunho etnográfico realizado com jovens estudantes, o pesquisador notou a concretização da matriz disciplinar de Rüsen durante o processo de aprendizagem, não obstante a aplicabilidade dos conceitos substantivos apreendidos fosse diferente do esperado pelos professores, já que depende das representações sociais de cada grupo.

Corroborando com essa ideia, Ribeiro (2006, p. 197) destacou que, na elaboração de "conceitos espontâneos", as ideias expressas por estudantes se assemelham a um "conceito impregnado de experiência pessoal, do qual a criança só adquire consciência relativamente tarde, quando é capaz de defini-lo em palavras com significado". A pesquisadora obteve essa conclusão após:

[...] identificar e analisar aspectos do processo de aprendizagem histórica mediante as representações construídas pelas crianças sobre os conceitos e informações trabalhados em aula, em atividades com a memória e a cultura material. (RIBEIR0, 2006, p. 19).

Tanto o pensamento de Moscovici quanto a teoria de Rüsen sugerem a construção de conhecimentos que podem ser compreendidos como fenômenos do mundo vital, isto é, 
calcados na experiência da vida cotidiana e orientados para a produção de comportamentos, práticas e constituição de sentidos. Inserida em uma relação temporal, a representação de um fenômeno contemporâneo aos participantes da pesquisa pode revelar um conjunto de saberes que influenciam em seus modos de articular as dimensões do passado, presente e futuro, e, consequentemente, no modo de perceber a História.

Por um lado, as representações sociais são definidas como "uma forma de conhecimento elaborada socialmente", como "produto e processo de uma atividade mental" (ABRIC, 2001, p. 13). Por sua vez, a consciência histórica encontra-se "embutida nos procedimentos e nas instituições, nos quais os seres humanos recebem seu cunho cultural ou [...] nos quais eles são “construídos'” (RÜSEN, 2014, p. 100). Juntas, elas podem funcionar como um "sistema de interpretação da realidade" (teoria das representações sociais) em uma perspectiva "temporal" (teoria da consciência histórica) que contribui para a orientação. As aproximações entre ambas as teorias, podem ser evidenciadas a partir de seus objetos e funções, conforme o quadro seguinte:

Quadro 1 - Comparação entre representações sociais e consciência histórica

\begin{tabular}{|c|c|c|}
\hline & Representações Sociais & Consciência Histórica \\
\hline Objeto & Senso comum & Memória \\
\hline \multirow{3}{*}{ Funções } & Explicar a realidade (facilitando a comunicação social) & $\begin{array}{l}\text { Contemplar a experiência da práxis vital } \\
\text { (precisando ser comunicada) }\end{array}$ \\
\hline & $\begin{array}{l}\text { Definir identidades (resguardando as especificidades do } \\
\text { grupo) }\end{array}$ & $\begin{array}{l}\text { Formar identidades (a partir de pretensões de } \\
\text { reconhecimento do grupo) }\end{array}$ \\
\hline & $\begin{array}{c}\text { Permitir a orientação e justificação (de comportamentos } \\
\text { e práticas) }\end{array}$ & Permitir a orientação (da ação humana no tempo) \\
\hline
\end{tabular}

Fonte: Elaboração própria com base em Abric (2001) e Rüsen (2014).

No campo das representações, o senso comum é um objeto originado na ciência que assume formas particulares na cultura. De maneira semelhante, a consciência histórica tem na memória (ou na cultura de memoração) um objeto que pode ser determinado "pelos produtores, receptores e mediadores da formação histórica de sentido, pelos modos de sua representação e pelos meios e instituições de sua mediação" (RÜSEN, 2014, p. 101-102). Em ambos os casos, as pessoas ou os grupos pensam por si e, desse modo, exibem respostas aos problemas que lhes são apresentados (MOSCOVICI, 2011). Por isso, podemos afirmar com Rüsen (2014, p. 103) que, a partir das ideias de senso comum ou da memória, "os seres humanos experimentam, motivam e normatizam, legitimam e criticam, transmitem e modificam a sua práxis vital individual ou coletiva”. Ao operacionalizar essas categorias (senso comum e memória), encontramos diferentes funções, algumas das quais equivalentes e que nortearão as discussões dos dados analisados adiante. 


\section{Método}

Neste estudo, seguimos os pressupostos da investigação qualitativa, a qual preconiza a necessidade de observação do objeto em seu ambiente natural e cujas abstrações são construídas ao longo da pesquisa. Assim, estivemos interessados nos modos como os sujeitos experimentaram, interpretaram e atribuíram sentidos ao fenômeno observado (BOGDAN; BIKLEN, 1994). Mesmo trabalhando com o universo "dos significados, dos motivos, das aspirações, das crenças, dos valores e das atitudes”, inspiramo-nos, também, no universo dos indicadores quantitativos, os quais viabilizaram uma "descrição matemática" do "pensamento" de nossos sujeitos (MINAY0, 2009, p. 21; MINAYO; SANCHES, 1993).

A pesquisa foi realizada em uma escola pública estadual, localizada no bairro Butantã, na cidade de São Paulo/SP, no ano de 2017. Participaram 127 estudantes, entre 14 e 18 anos de idade, dos gêneros masculino e feminino, distribuídos em cinco turmas do $1^{\circ}$ ano do Ensino Médio. A escola é composta por jovens que se declaram pardos (42,1\%), brancos $(27,4 \%)$, negros $(20,1 \%)$, amarelos $(6,7 \%)$ e indígenas $(3,7 \%)$. Convém ressaltar que esses/as participantes são oriundos de famílias compostas por 4 ou mais integrantes (75\%) e possuem uma renda mensal de até três salários-mínimos $(81,1 \%)$.

A coleta de dados foi realizada mediante autorização de coordenadores e professores. Desse modo, aplicamos um instrumento formado por 11 questões abertas, dentre as quais, buscamos investigar as ideias dos estudantes acerca do Brasil hodierno, dando ênfase ao modo como eles percebiam a si mesmos nesta dimensão temporal. Em seguida, intentamos perceber que tipo de fenômeno ou acontecimento do passado poderia ser evocado para explicar a situação do presente. Finalmente, incitamos os participantes à elaboração de perspectivas de futuro, tanto em relação ao seu país quanto ao seu papel nesse processo.

Inspirado nos estudos de Alves (2006) e Ribeiro (2006), além das perspectivas teóricas de Moscovici (2011) e Rüsen (2001, 2009, 2010a, 2014, 2015), o instrumento de pesquisa visou à construção de narrativas que contemplassem as dimensões temporais (passado, presente e futuro). Com isso, queríamos testar nossa hipótese de que as perspectivas acerca do momento vivido, em suas dimensões política, econômica, social e cultural, poderiam influenciar nos processos de ancoragem de eventos históricos, bem como de construção da consciência histórica dos/as jovens estudantes. Ademais, o instrumento viabilizou a introdução de elementos quantitativos por meio dos quais foi possivel "identificar a organização das respostas; expor os fatores explicativos ou as especificidades de uma amostragem, ou entre amostragens; identificar e situar as posições dos grupos estudados com relação aos eixos explicativos” (ABRIC, 2001a, p. 56, tradução nossa).

Fundamentada na Grounded theory de Strauss e Corbin (2008), a análise dos dados buscou estabelecer conceitos, delimitando suas propriedades e dimensões para a compreensão do fenômeno estudado. As respostas apresentadas ao instrumento de pesquisa foram coligidas em um único corpus - denominado Percepções sobre o Brasil - e submetidas ao IRAMUTEQ. Com auxílio desse programa computacional, realizamos uma Classificação Hierárquica Descendente (CHD), tipo de análise multivariada que viabiliza a construção de categorias baseadas na frequência das palavras, cuja representação gráfica é um dendograma (CAMARG0; JUST0, 2013). 


\section{Resultados}

Ao submeter o corpus textual ao IRAMUTEQ, o software fragmentou as respostas em 502 segmentos de texto (ST), dos quais 415 (82,67\%) foram considerados na análise. Os segmentos de texto apresentaram uma ocorrência média de 33,63 palavras, cuja frequência no corpus foi de 7,55 vezes. Para a construção do dendograma abaixo, consideramos as 10 palavras com maior frequência (f) e poder de associação à classe - qui-quadrado ( $\mathrm{x}^{2)}$.

Gráfico 1 - CHD do corpus Percepções sobre o Brasil

\begin{tabular}{|c|c|c|c|c|c|c|c|c|}
\hline \multicolumn{3}{|c|}{ Classe 1} & \multicolumn{3}{|c|}{ Classe 2} & \multicolumn{3}{|c|}{ Classe 3} \\
\hline \multicolumn{3}{|c|}{ Presente } & \multicolumn{3}{|c|}{ Passado } & \multirow{2}{*}{\multicolumn{3}{|c|}{$\begin{array}{c}\text { Futuro } \\
168 \text { ST }(40,48 \%)\end{array}$}} \\
\hline \multicolumn{3}{|c|}{137 ST $(33,01 \%)$} & \multicolumn{3}{|c|}{110 ST $(26,51 \%)$} & & & \\
\hline Palavras & $f$ & $x^{2}$ & Palavras & f & $x^{2}$ & Palavras & $f$ & $x^{2}$ \\
\hline Situação & 54 & 74.16 & escravidão & 20 & 49.46 & estudar & 70 & 82.82 \\
\hline Afetar & 43 & 61.00 & negro & 13 & 37.21 & imaginar & 28 & 37.49 \\
\hline Crise & 45 & 53.72 & passado & 34 & 28.76 & melhorar & 33 & 34.80 \\
\hline Brasil & 92 & 45.08 & racismo & 14 & 28.38 & trabalhar & 40 & 34.76 \\
\hline Caro & 13 & 27.23 & existir & 15 & 28.11 & faculdade & 22 & 34.16 \\
\hline Roubar & 21 & 26.17 & preconceito & 20 & 21.40 & futuro & 28 & 31.81 \\
\hline Ruim & 31 & 26.01 & mostrar & 9 & 17.75 & tentar & 21 & 29.14 \\
\hline Ficar & 23 & 25.69 & favorecer & 10 & 17.51 & ajudar & 28 & 26.95 \\
\hline Dinheiro & 24 & 20.19 & motivo & 7 & 15.58 & estudo & 16 & 21.16 \\
\hline Difícil & 20 & 20.04 & violência & 10 & 15.01 & bom & 41 & 19.90 \\
\hline
\end{tabular}

Fonte: Dendograma produzido com auxílio do IRAMUTEQ.

0 dendograma acima revela que o corpus Percepções sobre o Brasil sofreu duas partições. A primeira delas isolou a classe 3, separando-a das demais. Já a segunda, originou as classes 1 e 2 . Nessa divisão, observamos que a mais significativa foi a classe 3, com 40,48\% dos ST considerados na análise; seguido pela classe 1, com 33,01\%; e, a classe 2, com 26,51\%. Vejamos essas categorias mais detalhadamente a seguir.

\section{Representações do presente}

Conforme a classe 1, observamos a predominância de respostas cuja representação do país foi articulada ao presente, evidenciada, sobretudo, pelo substantivo "situação" ( $\mathrm{f}=54)$ : 
A situação do Brasil está ruim, mesmo eu não tendo quase nenhuma noção do como está, mas pelo o que a mídia diz está bem quebrado. (estudante 12, gênero masculino, 15 anos).

A situação do Brasil não é das melhores, está uma bagunça os políticos falam, e não fazem nada, muito assalto, vandalismo e desrespeito e etc. (estudante 72, gênero masculino, 14 anos).

Atualmente na situação do Brasil está tendo muita corrupção e roubo, por causa do governo estamos numa crise muito difícil. Muitas pessoas estão na fase de desemprego, sem moradia e isso que o governo disse que ia mudar e pra melhor estamos na espera. (estudante 270, gênero feminino, 16 anos).

A sociedade hoje em dia vem demonstrando alguns comportamentos que nos deixam indignados. Situações de corrupção, adolescentes usando drogas e muitas mortes, estamos passando por uma condição crítica e temos de superar. (estudante 271, gênero masculino, 14 anos).

Não obstante a desinformação ou a superficialidade das respostas para lidar com questões contemporâneas, os estudantes construíram diversas ideias, ainda que fragmentadas, acerca da situação atual do Brasil. Observamos que as narrativas privilegiam um momento complexo, cujos acontecimentos perpassam situações de ordem política e econômica, em que predominam a corrupção e a desonestidade; e problemas de ordem social, em que a violência e o abuso de drogas contribuem para a configuração de uma situação ancorada na ideia de "crise" ( $\mathrm{f}=45$ ). Na medida em que se intensificam, os episódios descritos "pioram" a vida dos brasileiros, "afetando" ( $\mathrm{f}=43$ ), em alguns casos, a eles próprios, como discorrem:

Não está afetando diretamente minha realidade nem minha família, pelo menos eu acho. Mas sei que a situação não está legal. (estudante 12, gênero masculino, 15 anos).

A situação atual do Brasil está afetando bastante qualquer família posso dizer que na minha também, tem pessoa esperando sair uma vaga de emprego, essa crise também não ajuda, né? Estamos numa fase muito difícil. Pois o governo que tá saindo por cima, porque ele que tá roubando. (estudante 270, gênero feminino, 16 anos).

Me afeta de várias formas, por exemplo, a segurança, posso sair de casa e levar um tiro ou tudo que trabalhei para conseguir ser roubado. (estudante 324, gênero masculino, 15 anos).

Afeta no preço de tudo porque pagamos muito imposto e as coisas deviam ser mais barata, pois pagamos muitos impostos e fora do Brasil as coisas é muito mais barata, pois lá fora eles não roubam igual roubam aqui no Brasil (estudante 296, gênero masculino, 14 anos).

Alguns participantes mantêm-se alheios aos acontecimentos recentes e preferem concordar com o discurso que circula, possivelmente, em seu ciclo de convivência. Outros, no entanto, destacam situações mais específicas, como o desemprego, o aumento com 
as despesas domésticas e a insegurança. Em uma concepção "radical”, as representações acima esboçadas poderiam ser entendidas como uma "criação" decorrente de práticas sociais, isto é, um "reflexo do modo de produção em que estão inseridos os indivíduos" (ABRIC, 2001b, p. 196).

Não obstante a importância desse aspecto, as representações também dependem de fatores culturais, além dos fatores ligados ao sistema de normas e valores, bem como à atividade do sujeito (ABRIC, 2001b). Engendradas mutuamente, práticas e representações sociais podem se transformar a partir de circunstâncias externas, entendidas como "qualquer estado do mundo fora da representação social" (FLAMENT, 2001, p. 45). Com isso, queremos dizer que, apesar de ser entendida como um elemento característico do presente, de um conjunto de ideias representativas acerca do Brasil, as percepções relacionadas a uma concepção de "crise" são flexíveis, podendo ser transformadas em situações diferentes.

Por um lado, essas ideias expressam um tipo de conhecimento popular (ou de senso comum) relacionado ao universo consensual que caracteriza as representações sociais (ÁLVARO; GARRIDO, 2006; CHAVES; SILVA, 2011). Por outro lado, não podemos desconsiderar tratar-se de diferentes "formas e funções do raciocínio e conhecimento histórico na vida cotidiana, prática” (RÜSEN, 2010, p. 32). Afinal, a consciência histórica constitui-se não apenas em ambiente escolar, mas também em espaços marcados pela expressão da "cultura histórica" a exemplo do cinema, teatro, museu, televisão, dentre outros tipos de mídia (CARDOS0, 2008; TATIAUX-GUILLON, 2011, RÜSEN, 2014).

\section{Articulações com o passado}

A classe 2 agrupou um conjunto de reflexões em torno do "passado" ( $f=34$ ) do Brasil. Acerca dessa dimensão temporal, cujo período não foi definido no instrumento de pesquisa, os jovens apresentaram diversas imagens, muitas das quais perpassaram a ideia de "escravidão" ( $f=20$ ). Questionados a respeito de como seria o passado, obtivemos respostas como:

Não acho que era agradável, pois tinha vários problemas de escravidão e tal, mas acho que a organização era melhor. (estudante 12, gênero masculino, 15 anos).

Ele era mais verde e com mais indígenas. E depois da colonização eles sofreram e depois veio a escravidão. 0 passado do Brasil muitos não tiveram um final feliz. (estudante 76, gênero masculino, 14 anos).

Ao comparar o passado colonial do Brasil ao momento atual, os estudantes são enfáticos quanto à superioridade dos problemas existentes naquele momento. Sem dúvidas, o fenômeno da escravidão foi tão avassalador que seus efeitos podem, ainda hoje, ser percebidos, seja por meio do "racismo" $(\mathrm{f}=14)$ ou de outros tipos de "preconceito" ( $\mathrm{f}=$ 20), conforme apontam: 
No Brasil do passado havia muita escravidão, muito mais racismo, etc., já o Brasil de hoje, a escravidão já diminuiu bastante, porém o racismo ainda existe. (estudante 28, gênero feminino, 15 anos).

Para mim o Brasil é um país que nunca vai mudar. Nós estamos no século XXI e ainda existe racismo, preconceito com as religiões e escravidão. (estudante 250, gênero feminino, 14 anos).

Muita discriminação racial, o preconceito predomina o Brasil hoje em dia. Muitos brancos quando vê um negro na rua, já pensa que ele é um ladrão, um criminoso e tal [...] do passado até hoje, o preconceito não acabou. (estudante 268, gênero feminino, 14 anos).

As atitudes de hostilidade étnica, religiosa e de gênero apontadas nas narrativas são percebidas por meio de um aprendizado que vai além do saber escolar. Os estudantes revelam experiências pessoais que lhes possibilitam falar sobre temas diretamente ligados aos grupos sociais dos quais participam. Dessa forma, mencionam o tratamento concedido ao "negro" ( $\mathrm{f}=13$ ) e, também, à "mulher" que, apesar de, hoje, "trabalhar no mercado de trabalho, porque não são consideradas tão inferior" (estudante 319, gênero feminino, 15 anos), já houve um período em que viviam "sem direito a nada" (estudante 65, gênero feminino, 14 anos), pois "não tinha voz ativa na sociedade" (estudante 11, gênero feminino, 14 anos). Ao endossar esse discurso, revelam o "preconceito" ( $f=20$ ) e a "violência" ( $f$ = 10) perpetrados contra grupos LGBT e indígena. Neste sentido, esboçam comparações entre eventos que ocorreram no passado e no presente:

No Brasil está acontecendo muitas coisas, [...] antigamente os ataques eram com as pessoas das religiões, como os judeus. A relação é que hoje em dia acontece a mesma coisa ataques nas religiões, mas além desse, tem ataques com os gays, pobres, negros, por causa do cabelo, etc. (estudante 26, gênero feminino, 15 anos).

0 preconceito antigamente era visto quase como se a pessoa fosse gay ou uma aberração pois as pessoas antigamente tudo era agredir, matar, etc. Agora só mudou um pouco pois botou a lei, mas mesmo assim tem pessoas que não seguem a lei e costuma com o preconceito de antigamente. (estudante 41, gênero feminino, 15 anos).

[...] antigamente que mandava aqui era os índios, mas os portugueses chegaram matando, estuprando e roubando e hoje ainda tem a mesma coisa. (estudante 34, gênero masculino, 14 anos).

Na medida em que revelam continuidades ou, pelo menos, situações mal resolvidas da nossa História, esses agentes históricos são utilizados para explicar a situação atual do Brasil, sobretudo em seu aspecto social ou cultural. Além dos referidos agentes, é preciso mencionar fenômenos e personagens lembrados nas narrativas, tais como:

Os golpes, rebeliões, violências. Com os golpes começou a existir leis e normas. Eles favoreceram negativamente, porque o mundo está com muita violência (estudante 267, gênero outros, 15 anos). 
Getúlio Vargas, se não me engano foi ele que fez a crise econômica no passado com as leis trabalhista [...]. A relação é que a sociedade e o governo influenciaram muitas coisas na população. [...] Favoreceram negativamente porque eles não estão fazendo nada para acabar com essa violência. (estudante 79, gênero feminino, 15 anos).

Ditadura, guerras, governo péssimo onde só ricos votava. Porque é parecido, porque até hoje, mulheres não tem o mesmo justo, e os ricos tem mais direitos. (estudante 323, gênero feminino, 15 anos).

Eneias, Bolsonaro, Lula, Dilma e Segunda Guerra Mundial o Brasil lutou. [...] Eu gostaria que deixassem pra lá algumas destas pessoas na merda que Hitler fazia. [...] infelizmente ainda existem outros como ele. [...] quem quer outra guerra por causa da cor da pele[?], Ninguém. Esses racistas como o Hitler, nunca mais vão chegar no poder novamente, isto é uma coisa positiva. (estudante 251, gênero masculino, 15 anos).

Em tais narrativas, percebemos a menção de fatos que, embora possam ser explicados de maneira equivocada ou superficial - quando há explicações -, exibem um panorama mais recente da História. Esses fatos envolvem acontecimentos políticos, como o golpe de 1964 e a ditadura militar no Brasil, bem como a Segunda Guerra Mundial e o nazismo alemão - ainda que citados de maneira velada. Paralelamente, surgem personagens como Getúlio Vargas, Lula, Dilma e Hitler, inseridos nas narrativas de maneira pouco articulada, sem a explicitação de seus papéis, por exemplo. Não obstante o passado de escravidão e seus efeitos serem relembrados com mais frequência, temas com uma proximidade temporal maior, a exemplo dos supracitados, também foram rememorados para justificar um momento específico: a "crise" ( $\mathrm{f}=45)$ no Brasil.

\section{Projeções para o futuro}

Finalmente, a classe 3 apontou ideias relativas ao "futuro" ( $f=28)$. Neste momento, procuramos entender não apenas como os jovens participantes projetavam o futuro do Brasil, mas, sobretudo, como se colocavam nesse exercício de reflexão. Dentre os projetos de ordem pessoal, destacou-se o desejo de obtenção de uma carreira profissional bemsucedida, iniciada pelos estudos e culminando com um bom emprego. Além disso, os estudantes revelavam o anseio de constituir família e adquirir bens próprios, como casa e carro. A estratégia para tanto é observada no emprego da palavra mais frequente $(\mathrm{f}=70)$ e de maior poder de associação à classe $\left(x^{2}=82,82\right)$ : "estudar".

Eu me vejo casada, com minha casa, meu carro, minha moto, não quero estar no Brasil pretendo estar com uma financeira bem. [...] Estou estudando, vou começa a trabalhar para eu poder ter dinheiro para conseguir realizar isso. (estudante 78, gênero feminino, 15 anos).

Como pai, com uma família, já trabalhando e tendo minha própria casa. [...] Estudando, fazendo curso e aprendendo. (estudante 47, gênero masculino, 15 anos). 
Ainda que considerem os estudos como elemento importante na realização desses desejos, os jovens não deixam de considerar as dificuldades alheias aos seus esforços, advindas sobretudo, das conjunturas econômicas e sociais do país:

Se continuar dessa maneira, me vejo tendo dificuldade em quesito de dinheiro. Se meu sonho der certo, estarei terminando a faculdade de medicina e pesquisando, talvez morar em outro país. [...] Me esforçando muito, dando meu máximo. Estudo todos os dias após chegar da escola, pretendo fazer um cursinho no $3^{\circ}$ ano para prestar o vestibular, o famoso ENEM. E passar na faculdade. (estudante 11, gênero feminino, 14 anos).

Com o país de hoje não dá pra saber porque as coisas só pioram para o povo, mas quero estar trabalhando e estabilizado financeiramente. [...] Estudando. (estudante 306, gênero masculino, 15 anos).

Quanto às expectativas em relação ao Brasil no futuro, observamos que, agora, as incertezas sobre o momento atual deram margem ao reconhecimento de uma situação complexa, permeada de dificuldades que não podem "continuar":

Se caso continuar desse jeito estará praticamente inabitável, mas se houverem mudanças de leis e fazer com que o cidadão tenha a possibilidade de sair nas ruas, ao menos sem medo, (estudante 33, gênero masculino, 14 anos).

Se continuar do jeito que está, as pessoas estarão mais pobres, e os que são ricos mais ricos, como prefeitos e deputados. (estudante 26, gênero feminino, 15 anos).

Se continuar desta maneira a economia do Brasil vai afundar, educação e saúde vão ser definitivamente deixado de lado. (estudante 283, gênero feminino, 14 anos).

Novamente, essas projeções parecem estar associadas a problemas sociais, como a violência urbana e a desigualdade econômica. Além disso, também é evidenciado o receio aos projetos governamentais, como as reformas da previdência e do Ensino Médio. Portanto, na opinião dos estudantes, é preciso haver mudanças capazes de reconstruir o país. Nesse sentido, uma série de melhorias relacionadas à saúde, à educação e à moradia são sugeridas quando questionados sobre o que fariam, caso fossem presidentes:

Faria uma mudança radical para a educação pública do Brasil, investiria muito mais na segurança e bem-estar dos cidadãos, melhoraria a saúde pública que está precária. E o mais importante, eu ouviria o povo, faria o impossível para ninguém se prejudicar e conviver em harmonia. (estudante 11, gênero feminino, 14 anos).

Primeiramente, iria mudar todo o governo, acabar com as corrupções, tirar os moradores de rua da rua para os acolherem e dá-los os direitos que todo brasileiro tem, investir na educação pública e no país. (estudante 318, gênero feminino, 14 anos). 
Investiria em mais educação e faria leis mais duras para uns crimes que eu considero repugnantes, mas, nossa, que viagem: eu, presidente. (estudante 12, gênero masculino, 15 anos).

Mesmo apresentando respostas bem-humoradas acerca da situação hipotética que os conduziu a pensar no futuro, os jovens emitiram opiniões sérias, capazes de revelar situações que afligem o cotidiano da população brasileira. Tais respostas revelam, sobretudo, a insatisfação com os diversos tipos de desigualdade vivenciada por significativa parte do grupo pesquisado, sejam elas relacionadas a aspectos econômicos, culturais ou sociais. Comparando as expectativas individuais e coletivas acerca do futuro, observamos ideias um tanto contraditórias. Por um lado, não obstante o reconhecimento de dificuldades no presente, os estudantes projetam seu futuro individual como bemsucedido. Em contrapartida, o país em que vivem estará enfrentando situações ainda mais problemáticas. Essa constatação pode sugerir, ainda que sutilmente, a dificuldade do estudante em se enxergar como um sujeito ativo da História.

\section{Discussões}

A partir do diálogo entre as teorias da consciência histórica e das representações sociais, analisamos as percepções de jovens estudantes acerca do Brasil. Nesse sentido, perscrutamos narrativas que revelaram um conjunto de ideias centradas em acontecimentos recentes, mas que permeou temporalidades distintas, articulando conhecimentos acerca do passado e estabelecendo projeções de futuro. Tais percepções converteram-se na formação de uma "consciência temporal humana, na qual a experiência do passado enquanto História [foi] interpretada para o presente” (RÜSEN, 2014, p. 97).

De maneira geral, os estudantes demonstraram interesse em responder ao questionário, mesmo não apresentando domínio sobre os conteúdos evocados. Esse posicionamento configurou-se como uma necessidade - poderíamos dizer, um compromisso - de "avaliar seres e objetos corretamente, de compreender a realidade completamente" (MOSCOVICI, 2011, p.30). Ao fazê-lo, os jovens produziram narrativas que consideramos históricas, tendo em vista a atualização de uma experiência do passado, conectada de maneira relativa e significante com o presente, com o fito de estabelecer orientação no tempo (RÜSEN, 2010).

Como exemplo desse processo cognitivo, podemos destacar os recuos feitos pelos estudantes que mobilizaram no passado temas como escravidão e preconceito para compreender a situação do presente, ideias possivelmente relacionadas a autorreferenciação desses jovens, em sua maioria pardos ou negros. 0 passado delineado nas narrativas converteu-se em problemas, a exemplo da geração de desemprego e insegurança que, por sua vez, encetaram um futuro ainda mais obscuro, com a ampliação dessas mesmas questões. Marcadas por ideias de senso comum ou mesmo, por um conjunto de memórias, as narrativas dos participantes evidenciaram funções que poderiam ser relacionadas tanto a teoria das representações sociais quanto a teoria da consciência histórica.

Inicialmente, com o fito de contemplar a experiência, os estudantes encetaram uma “laboração intelectual de problemas e desafios da práxis vital” (RÜSEN, 2014, p. 105), por meio da qual: 
[...] as memorações brota[ra]m de uma constelação problemática entre sujeito e objeto e est[avam] fundadas na faculdade humana de responder culturalmente à realidade de um mundo precário e contingente com a formação de estruturas de sentido. (RÜSEN, 2014, p. 105).

Desse modo, percebemos como os jovens participantes foram capazes de apreender os acontecimentos do presente, estimulados por uma interpretação do passado que lhes garantiu o desenvolvimento de orientações com significado cultural.

Considerando a necessidade de transmissão dessas representações do passado, foi preciso "ingressar num processo comunicativo, no qual um problema de orientação da própria práxis vital [foi] interpretada mediante um intercâmbio recíproco entre os envolvidos" (RÜSEN, 2014, p. 107). A reação humana diante de experiências contingenciais, bem como seu contexto de comunicações poderiam ser muito bem associados à necessidade de explicar a realidade, conforme a função advinda da teoria das representações sociais. À luz desse modelo teórico, observamos como a consciência histórica propiciou a aquisição e integração de conhecimentos em marcos assimiláveis e compreensíveis para os jovens estudantes.

Em seguida, evidenciamos pretensões de reconhecimento do grupo por meio de narrativas que perpassaram significados simbólicos, normativos, cognitivos e estéticos, garantindo, assim, uma percepção identitária. Com base nesse aspecto, os indivíduos foram capazes de atribuir à História um nexo de sentido "que elev[ou] a diferença das dimensões temporais e a falta de concatenação entre o acontecido à unidade de uma continuidade trazida para o presente, possibilitando, assim, orientação na mudança do tempo" (RÜSEN, 2014, p. 112). Além disso, inferimos que as ideias aventadas pelos participantes elucidaram a capacidade humana de "transcender-se culturalmente, isto é, de constantemente estabelecer novos limites para depois, mais uma vez, voltar a transcendêlos” (RÜSEN, 2014, p. 114).

Finalmente, observamos uma variedade de comportamentos ou práticas que garantiram a percepção de diferentes formas de orientação. Em uma perspectiva sóciohistórica e cultural, vislumbramos o reconhecimento de uma multiplicidade de fatores (intencionais e contingenciais) que interferiram na ação humana para garantir uma atualização da História. Ainda que seja possível evidenciar narrativas relacionadas a esse tipo ideal, os mecanismos de orientação aventados pelos jovens em suas representações do passado demonstraram, sobretudo, a necessidade de produzir antecipações e expectativas, tornando-se, portanto, "um guia para a ação" (ABRIC, 2001, p. 16).

\section{Considerações finais}

Realizada em 2017, a pesquisa capturou, em alguma medida, os impactos de um período conturbado de nossa História recente, a saber, o impeachment da presidenta Dilma Rousseff e a ascensão de Michel Temer. Mesmo não discutindo de maneira aprofundada esses eventos e, apenas, tangenciando-os, nossos participantes expuseram ideias que demonstraram a influência de perspectivas do momento vivido nos processos de ancoragem de eventos históricos, bem como de construção da consciência histórica - confirmando, portanto, nossa hipótese inicial. Contudo, muito mais do que evidenciar 
conhecimentos históricos apreendidos em situação escolar, os jovens pareceram aderir a um tipo de discurso bastante comum entre os meios de comunicação de massa.

Embora reconheçamos o valor dos saberes oriundos de outros espaços, seja para a formação da consciência histórica, seja para a construção de representações sociais, não nos debruçamos acerca das influências midiáticas na percepção dos jovens participantes, o que se revela como uma possibilidade de estudo bastante promissora.

Ainda assim, a análise dos dados revelou a identificação de ideias relacionadas à percepção de um país em crise, com um passado preconceituoso e um futuro, contraditoriamente, promissor. Esse descompasso entre a dimensão passado-presente comparada à dimensão futuro talvez seja reveladora da dificuldade que o jovem tem de se perceber como um agente histórico. Por esse motivo, destacamos a importância de um planejamento docente que seja capaz de considerar os sentidos históricos prévios dos/as estudantes. A partir dessas percepções, o professor ou a professora poderá contribuir com a formação da consciência histórica, de maneira a ampliar a capacidade crítica do estudante, para quem o passado deve converter-se em um presente com utilidade para a vida.

\section{Referências}

ABRIC, Jean-Claude. Las representaciones sociales: aspectos teóricos. In: ABRIC, Jean-Claude (ed.). Prácticas sociales y representaciones. México, DF: Coyoacán, 2001. p. 11-32.

ABRIC, Jean-Claude. Metodología de recolección de las representaciones sociales. In: ABRIC, Jean-Claude (ed.). Prácticas sociales y representaciones. México, DF: Coyoacán, 2001a. p. 53-74.

ABRIC, Jean-Claude. Prácticas sociales, representaciones sociales. In: ABRIC, Jean-Claude (ed.). Prácticas sociales y representaciones. México, DF: Coyoacán, 2001b. p. 195-214.

ALMEIDA, Angela Maria de Oliveira; SANTOS, Maria de Fátima de Souza. A teoria das representações sociais. In: TORRES, Cláudio Vaz; NEIVA, Elaine Rabelo (org.). Psicologia social: principais temas e vertentes. Porto Alegre: Artmed, 2011. p. 287-295.

ÁlVARO, José Luis; GARRID0, Alicia. A teoria das representações sociais. In: ÁLVARO, José Luis; GARRIDO, Alicia. Psicologia social: perspectivas psicológicas e sociológicas. São Paulo: McGraw-Hill, 2006. p. 286-292.

ALVES, Ronaldo Cardoso. Representações sociais e a construção da consciência histórica. 2006. 133 f. Dissertação (Mestrado em Educação) - Universidade de São Paulo, São Paulo, 2006.

ASSIS, Arthur. A teoria da história de Jörn Rüsen: uma introdução. Goiânia: UFG, 2010.

BOGDAN, Robert C.; BIKLEN, Sari Knopp. Investigação qualitativa em educação: uma introdução à teoria e aos métodos. Porto: Porto Editora, 1994.

CAIMI, Flávia Eloisa. Investigando os caminhos recentes da história escolar: tendências e perspectivas de ensino e pesquisa. In: ROCHA, Helenice; MAGALHÃES, Marcelo; GONTIJO, Rebeca (org.). 0 ensino de história em questão: cultura histórica, usos do passado. Rio de Janeiro: FGV, 2015. p. 17-36. 
CAMARG0, Brígido Vizeu; JUSTO, Ana Maria. IRAMUTEQ: um software gratuito para análise de dados textuais. Temas em Psicologia, Ribeirão Preto, v. 1, n. 2, p. 513-518, 2013. Disponível em: http://pepsic. bvsalud.org/pdf/tp/v21n2/v21n2a16.pdf. Acesso em: 20 jul. 2016.

CARDOSO, Ciro Flamarion. 0 uso, em história, da noção de representações sociais desenvolvida na psicologia social: um recurso metodológico possível. Psicologia e Saber Social, Rio de Janeiro, v. 1, n. 1, p. 40-52, 2012. Disponível em: https://www.e-publicacoes.uerj.br/index.php/psi-sabersocial/article/ view/3244. Acesso em: 11 set. 2018.

CARDOSO, Oldimar. Para uma definição de didática da história. Revista Brasileira de História, São Paulo, v. 28, n. 55, p. 153-170, 2008. Disponível em: http://www.scielo.br/pdf/rbh/v28n55/a08v28n55.pdf. Acesso em: 22 abr. 2015.

CHAVES, Antônio Marcos; SILVA, Priscila de Lima. Representações sociais. In: CAMINO, Leôncio et al. (org.).

Psicologia social: temas e teorias. Brasília: Technopolitik, 2011. p. 299-349.

FLAMENT, Claude. Estructura, dinámica y transformación de las representaciones sociales. In: ABRIC, Jean-Claude (ed.). Prácticas sociales y representaciones. México, DF: Coyoacán, 2001. p. 33-52.

GUIMARÃES, Selva. Revisitando a história da disciplina. In: GUIMARÃES, Selva. Didática e prática de ensino de história. 13. ed. Campinas: Papirus, 2012. p. 19-38.

MINAYO, Maria Cecília de Souza. 0 desafio da pesquisa social. In: MINAYO, Maria Cecília de Souza; DESLANDES, Suely Ferreira; GOMES, Romeu (org.). Pesquisa social: teoria, método e criatividade. 28. ed. Petrópolis: Vozes, 2009. p. 9-29.

MINAYO, Maria Cecília de Souza; SANCHES, Odécio. Quantitativo-qualitativo: oposição ou complementaridade? Cadernos de Saúde Pública, Rio de Janeiro, v. 9, n. 3, p. 239-262, jul./set. 1993. Disponível em: http://www.scielo.br/pdf/\%0D/csp/v9n3/02.pdf. Acesso em: 28 nov. 2019.

MOSCOVICI, Serge. La psychanalyse, son image et son public. Paris: Presses Universitaires de France, 1961. MOSCOVICI, Serge. Representações sociais: investigações em psicologia social. 8. ed. Petrópolis: Vozes, 2011.

OLIVEIRA, Margarida Maria Dias de. 0 direito ao passado: uma discussão necessária à formação do profissional de história. 2003. 291 f. Tese (Doutorado em História) - Universidade Federal de Pernambuco, Recife, 2003.

RIBEIR0, Regina Maria de Oliveira. A "máquina do tempo": representações do passado, história e memória na sala de aula. 2006. 272 f. Dissertação (Mestrado em Educação) - Universidade de São Paulo, São Paulo, 2006.

RÜSEN, Jörn. Como dar sentido ao passado: questões relevantes de meta-história. História da Historiografia, Ouro Preto, n. 2, p. 163-209, mar. 2009. Disponível em: https://www.historiadahistoriografia.com.br/ revista/article/view/12. Acesso em: 22 mar. 2017. 
RÜSEN, Jörn. Cultura faz sentido: orientações entre 0 ontem e 0 amanhã. Tradução Nélio Schnider. Petrópolis: Vozes, 2014.

RÜSEN, Jörn. Didática da história: passado, presente e perspectivas a partir do caso alemão. In: SCHMIDT, Maria Auxiliadora; BARCA, Isabel; MARTINS, Estevão de Rezende (org.). Jörn Rüsen e o ensino de história. Curitiba: UFPR, 2010. p. 23-40.

RÜSEN, Jörn. Narrativa histórica: fundamentos, tipos, razão. In: SCHMIDT, Maria Auxiliadora; BARCA, Isabel; MARTINS, Estevão de Rezende (org.). Jörn Rüsen e o ensino de história. Curitiba: UFPR, 2010a. p. 93-108.

RÜSEN, Jörn. Razão histórica: teoria da história: os fundamentos da ciência histórica. Tradução Estevão de Rezende Martins. Brasília, DF: Universidade de Brasília, 2001.

RÜSEN, Jörn. Teoria da história: uma teoria da história como ciência. Tradução Estevão C. de Rezende Martins. Curitiba: UFPR, 2015.

SÁ, Celso Pereira de. Núcleo central das representações sociais. 2. ed. Petrópolis: Vozes, 2002.

STRAUSS, Anselm; CORBIN, Juliet. Pesquisa qualitativa: técnicas e procedimentos para o desenvolvimento de teoria fundamentada. 2. ed. Porto Alegre: Artmed, 2008.

TATIAUX-GUILLON, Nicole. 0 paradoxo francês: cultura histórica significativa e didática da história incerta. Educação \& Realidade, Porto Alegre, v. 36, n. 1, p. 15-37, jan./abr. 2011. Disponível em: https://seer. ufrgs.br/educacaoerealidade/article/view/15162. Acesso em: 29 ago. 2015.

Recebido em: 28.07.2019

Revisado em: 12.11.2019

Aprovado em: 18.02.2020

Aaron Sena Cerqueira Reis é doutor em educação pela Universidade de São Paulo (USP). Atualmente é professor na Universidade Tiradentes, campus Aracaju.

Joilson Pereira da Silva é doutor em psicologia pela Universidade Complutense de Madri. Atualmente é professor na Universidade Federal de Sergipe. 